\title{
EPIGENETIC ALTERATIONS IN PATIENTS WITH TYPE 2 DIABETES MELLITUS
}

\author{
Karachanak-Yankova $\mathrm{S}^{1, \mathrm{a}}$, Dimova $\mathrm{R}^{2, \mathrm{a}}$, Nikolova $\mathrm{D}^{1}$, Nesheva $\mathrm{D}^{1}$, Koprinarova $\mathrm{M}^{3}$, \\ Maslyankov $\mathrm{S}^{4}$, Tafradjiska $\mathrm{R}^{5}$, Gateva $\mathrm{P}^{6}$, Velizarova $\mathrm{M}^{7}$, Hammoudeh $\mathrm{Z}^{1}$, Stoynev $\mathrm{N}^{2}$, \\ Toncheva $\mathrm{D}^{1}$, Tankova $\mathrm{T}^{2}$, Dimova I $\mathrm{I}^{1, *}$
}

*Corresponding Author: Ivanka Dimova, Associate Professor, Department of Medical Genetics, Medical University Sofia, Zdrave str. 2, 1431 Sofia, Bulgaria. Tel: +359-2-91-72-735. E-mail: ivanka.i.dimova@ gmail.com

\begin{abstract}
Epigenetic changes, in particular DNA methylation processes, play a role in the pathogenesis and progression of type 2 diabetes mellitus (T2DM) linking genetic and environmental factors. To clarify this role, we have analyzed in patients with different duration of T2DM: (i) expression levels of methylCpG-binding domain protein 2 (MBD2) as marker of DNA methylation, and ii) methylation changes in 22 genes connected to cellular stress and toxicity. We have analyzed $M B D 2 \mathrm{mRNA}$ expression levels in 16 patients and 12 controls and the methylation status of stress and toxicity genes in four DNA pools: (i) controls; (ii) newly-diagnosed T2DM patients; (iii) patients with T2DM duration of $<5$ years and (iv) of $>5$ years. The $M B D 2$ expression levels were
\end{abstract}

\footnotetext{
S. Karachanak-Yankova and R. Dimova contributed equally to this study.

${ }^{1}$ Department of Medical Genetics, Medical Faculty, Medical University of Sofia, Sofia, Bulgaria

${ }^{2}$ University Specialized Hospital for Active Treatment of Endocrinology ‘Acad. Ivan Penchev,' Sofia, Bulgaria

${ }^{3}$ Institute of Molecular Biology, Bulgarian Academy of Sciences, Sofia, Bulgaria

${ }^{4}$ Department of Surgery, Medical Faculty, Medical University of Sofia, Sofia, Bulgaria

${ }^{5}$ Department of Pathophysiology, Medical Faculty, Medical University of Sofia, Sofia, Bulgaria

${ }^{6}$ Department of Pharmacology and Toxicology, Medical Faculty, Medical University of Sofia, Sofia, Bulgaria

7 Clinical Laboratory, University Hospital 'Aleksandrovska,' Sofia, Bulgaria
}

10.4-times increased on average in T2DM patients compared to controls. Consistent increase in DNA methylation fraction with the increase in T2DM duration was observed in $P r d x 2$ and SCARA3 genes, connected to oxidative stress protection and in $B R C A 1$ and $T p 53$ tumor-suppressor genes. In conclusion, increased $M B D 2$ expression in patients indicated general dysregulation of DNA methylation in T2DM. The elevated methylation of $P r d x 2$ and SCARA3 genes suggests disturbance in oxidative stress protection in T2DM. The increased methylation of $B R C A 1$ and $T p 53$ genes unraveled an epigenetic cause for T2DM related increase in cancer risk.

Keywords: DNA methylation; Epigenetic changes; Methyl-CpG-binding domain protein 2 (MBD2); Stress and toxicity genes; Tumorigenesis; Type 2 diabetes mellitus (T2DM)

\section{INTRODUCTION}

Type 2 diabetes mellitus (T2DM) is characterized by hyperglycemia arising from insulin resistance combined with relative insulin deficiency. As hyperglycemia becomes chronic, it leads to oxidative stress, which is one of the central mechanisms for glucose toxicity. It is the proximate cause of retinopathy, kidney failure, neuropathies, and macrovascular disease in diabetes [1].

The genetic basis for developing T2DM has been recognized for a long time. The concordance of T2DM in monozygotic twins is $\sim 70.0 \%$ compared with $20.0-30.0 \%$ in dizygotic twins and a sibling of an 
affected individual has about three times higher risk for developing the disorder than the general population [2].

The decades of research into the genetic causes of T2DM have culminated with a succession of large genome-wide association studies. Despite their power and cost, they have identified genetic variants that increase T2DM risk by only $10.0-30.0 \%$ [3-5].

The incidence of T2DM has increased dramatically over the past decades [6], which is a too short period for accumulation of considerable alterations in the human genome. Therefore, it is likely that environmental factors, such as diet and sedentary lifestyle, might play a significant role in the development of the disease.

The role of epigenetic factors in the gene environment interactions pointed to epigenetics as a possible molecular link between environmental factors and T2DM. Previous studies have shown that epigenetic mechanisms can predispose individuals to the diabetic phenotype. Conversely, the altered homeostasis in T2DM, such as prolonged hyperglycemia, dyslipidemia and increased oxidative stress could also cause epigenetic changes associated with the development of disease complications [7].

The operational definition of epigenetics proposes three successive signals for the establishment of the epi-genetic state: an environmental signal (i) that triggers a second intracellular signal, (ii) to establish the exact chromatin location where the modification will take place, and (iii) a third sustaining signal that helps maintain this modification. The epigenetic make-up changes during intrauter-ine and early postnatal development, as well as throughout adult life [8].

A classic example of epigenetic transcriptional regulation is the covalent post replicative methylation of DNA at the fifth position of the cytosine ring of $\mathrm{CpG}$ dinucleotides. DNA methylation is a highly dynamic process in development and disease. It is strongly associated with gene silencing and decreased gene expression [9]. The functional significance of DNA methylation alterations became apparent with their recognition as critical contributors to the pathogenesis of cancer, acting by silencing of tumor suppressor genes [10]. There is convincing evidence that DNA methylation is performed by DNA methyltransferases (DNMTs). DNMT1 is essential for maintaining DNA methylation patterns in proliferating cells as it methylates $\mathrm{CpG}$ dinucleotides in the newly synthesized strand and DNMT3a and DNMT3b are necessary for de novo meth-ylation during embryonic development [11].

The biological consequences of DNA methylation are mediated by a family of methyl-CpG binding domain (MBD) proteins. Among these, only MBD2 seems to be specific for methyl-CpG sites alone. It directs a multi subunit complex containing nucleosome remodeling and histone deacetylase activities to methylated DNA, thus leading to gene silencing [12].

Taking into account the role of epigenetics in the pathogenesis of type 2 diabetes mellitus, we have per-formed analysis of $M B D 2$ expression levels in T2DM patients and controls. Considering also that altered metabolic homeostasis and increased oxidative stress in T2DM can trigger epigenetic changes that can lead to disease complications, we calculated the fractions of DNA methylation of 22 genes related to stress and toxicity in groups of healthy controls and T2DM patients with different duration of the disease, newly-diagnosed and with disease duration of less and more than 5 years.

Based on the obtained results, we answered the following questions: i) are there any $M B D 2$ expression-related changes in DNA methylation in the pathogenesis of T2DM; ii) what is the role of the epigenetic changes in 22 genes related to stress and toxicity in T2DM pathogenesis and progression; and iii) are these changes related to the increased risk of oncological disorders in T2DM patients.

\section{MATERIALS AND METHODS}

Subjects. We collected blood samples from healthy controls $(n=12)$ and T2DM patients $(n=27)$. The patients were subdivided according to diabetes duration: newly-diagnosed T2DM $(n=9)$; T2DM duration of $\leq 5$ years $(n=9)$; and T2DM duration of $>5$ years $(n=9)$.

The participants were recruited at the Department of Diabetology, Clinical Centre of Endocrinology at the Medical University, Sofia, Bulgaria. All subjects provided written informed consent and were familiar with the aims, methods and risks of participating in the study in accordance with the Helsinki Declaration and rules of Good Clinical Practice. The study was approved by the Ethics Committee of the Medical University, Sofia, Bulgaria. 
Methods. The patients were interviewed for T2DM duration, presence of arterial hypertension and other chronic diseases. Body mass index (BMI) was calculated. Arterial blood pressure was measured in standard conditions. Laboratory parameters were measured in all participants at fasting: $\mathrm{Hb} \mathrm{A}_{1 \mathrm{c}}$ in whole blood by immuneturbidimetric method (Roche Diagnostics Deutschland GmbH, Mannheim, Germany); total cholesterol, high density lipoprotein (HDL) cholesterol, and triglycerides by enzymatic colorimetric method (Roche Diagnostics); low density lipoprotein (LDL) cholesterol was calculated using Fridewald's formula. The 2005 International Diabetes Federation (IDF) definition of the metabolic syndrome (MetS) was used. The main characteristics of the subgroups are summarized in Table 1.

A subset of the blood samples from the patients $(n=16)$ and controls $(n=12)$ were used for total RNA purification for the analysis of the $M B D 2$ gene expression. The epigenetic changes in the 22 genes related to stress and cell cycle regulation were analyzed in DNA specimens extracted from all blood samples.

MBD2 mRNA Expression Analysis. RNA was purified using QIAamp ${ }^{\circledR}$ RNA Blood Kit (Qiagen $\mathrm{GmbH}$, Hilden, Germany). An amount of $250 \mathrm{ng}$ of each RNA sample was reverse transcribed to cDNA (QuantiTect Reverse Transcription kit; Qiagen). The cDNAs were further examined using the quantitative polymerase chain reaction (qPCR) Primer Assay for Human MBD2 (Cat. \#PPH08621A-200; Qiagen). The real-time PCR (RT-PCR) amplification was performed on an ABI PRISM ${ }^{\circledR} 7500$ instrument and the results were analyzed with ABI PRISM ${ }^{\circledR}$ Sequence Detection Software, ver.1.4.0 (Applied Biosystems, Foster City, CA, USA). The total volume of each reaction was $50 \mu \mathrm{L}$ with less than $100 \mathrm{ng}$ cDNA per reaction. The amplification conditions of each RTPCR cycle were as follows: denaturation at $94{ }^{\circ} \mathrm{C}$ for 15 seconds, primer annealing at $55^{\circ} \mathrm{C}$ for 30 seconds, followed by primer extension at $72{ }^{\circ} \mathrm{C}$ for 30 seconds. The expression levels of $M B D 2$ were normalized to glyceraldehyde-3-phosphate dehydrogenase (GAPDH) using the $\triangle \triangle \mathrm{CT}$ method. In order to avoid contamination, we included an internal non template control in each run.

DNA Methylation Analysis of 22 Stress and Toxicity Genes. Whole genome DNA was extracted using DNeasy Blood \& Tissue Kit (Qiagen). The DNA samples were combined into four DNA pools each of nine healthy controls, newly-diagnosed T2DM patients, patients with T2DM duration of less and more than 5 years. DNA in each pool was adjusted to a final concentration of $50 \mathrm{ng} / \mu \mathrm{L}$. Each DNA pool was analyzed for the promoter methylation status of 22 genes included in the Human Stress \& Toxicity PathwayFinder EpiTect Methyl II Signature PCR Array (Qiagen Sciences Inc., Germantown, MD, USA) (Table 2). The method is based on detection of remaining input DNA after cleavage with a methylation-sensitive and/or a methylationdependent restriction enzyme. These enzymes will digest unmethylated and methylated DNA, respectively. Following digestion, the remaining DNA in each individual enzyme reaction is quantified by RT-PCR using primers that flank a promoter (gene)

Table 1. Main characteristics (number, gender distribution, mean age, BMI, $\mathrm{Hb} \mathrm{A}_{1 \mathrm{c}}$, diabetes duration, presence of MetS, arterial hypertension, chronic complications of diabetes of the participants in the subgroups according to diabetes duration: newly-diagnosed T2DM, T2DM duration of $\leq 5$ years, and T2DM duration $>5$ years).

\begin{tabular}{|l|c|c|c|}
\hline Parameters & $\begin{array}{c}\text { Newly-Diagnosed } \\
\text { T2DM }\end{array}$ & $\begin{array}{c}\text { T2DM Duration } \\
\text { 55 Years }\end{array}$ & $\begin{array}{c}\text { T2DM Duration } \\
\text { >5 Years }\end{array}$ \\
\hline Number & 9 & 9 & 9 \\
\hline Sex & 6 males; 3 females & 5 males; 4 females & 5 males; 4 females \\
\hline Age (years) $($ mean \pm SD) & $62.0 \pm 7.5$ & $51.3 \pm 14.0$ & $55.7 \pm 7.7$ \\
\hline BMI $\left(\mathrm{kg} / \mathrm{m}^{2}\right)$ & $34.8 \pm 8.4$ & $38.1 \pm 13.7$ & $34.0 \pm 2.7$ \\
\hline Hb A 1 (\%) & $7.9 \pm 2.3$ & $8.8 \pm 1.8$ & $8.7 \pm 2.1$ \\
\hline Duration (years) & 0.0 & $2.2 \pm 0.8$ & $6.8 \pm 1.9$ \\
\hline MetS (\%) & $7 / 9(77.8)$ & $6 / 9(66.7)$ & $9 / 9(100.0)$ \\
\hline Arterial hypertension $(\%)$ & $6 / 9(66.7)$ & $8 / 9(88.9)$ & $8 / 9(88.9)$ \\
\hline Chronic complications of diabetes $(\%)$ & $2 / 9(22.2)$ & $8 / 9(88.9)$ & $8 / 9(88.9)$ \\
\hline
\end{tabular}

T2DM: type 2 diabetes mellitus; mean \pm SD: mean \pm standard deviation; BMI: body mass index; MetS: metabolic syndrome. 
Table 2. List of 22 analyzed genes and the processes they mediate.

\begin{tabular}{|l|l|}
\hline Genes & Processes Mediated by the Genes \\
\hline Bnip3, Cyp1a1, Gpx3, Prdx2, Ptgs2 (Cox2) & Oxidative stress \\
\hline Atm, Brca1, Ccnd1, Gadd45a, Gadd45g, Mlh1, Msh2, Tp53 & DNA damage \\
\hline Insig1, Ube2g2 & Unfolded protein response \\
\hline Cstb, Rara & Hypoxia \\
\hline Dnajc15 & Heat shock protein \\
\hline Atm, Cdkn1a (P21cip1/Waf1), Gadd45a (Plab), Msh2, Tp53 & Growth arrest and senescence \\
\hline Prdx2, Ptgs2 (Cox2) & Inflammation \\
\hline Bnip3, Cdkn1a (P21cip1/Waf1), Prdx2 & Anti-apoptosis \\
\hline Brca1, Ccnd1, Cdkn1a (P21cip1/Waf1), Cyp1a1, Prdx2 & Proliferation and carcinogenesis \\
\hline
\end{tabular}

region of interest. The relative fractions of methylated and unmethylated DNA are subsequently determined by comparing the amount in each digest with that of a mock (no enzymes added) digest using a $\Delta \mathrm{CT}$ method. Unmethylated represents the fraction of input genomic DNA containing no methylated $\mathrm{CpG}$ sites in the amplified region of a gene. Methylated represents fraction of input genomic DNA containing two or more methylated $\mathrm{CpG}$ sites in the targeted region of a gene. Data quality control parameters were strictly accomplished according to the protocol of the manufacturer.

\section{RESULTS}

Expression Profile of $\mathbf{M B D 2}$ in Patients with T2DM. The gene expression analysis of $M B D 2$ performed for each of the 12 controls and 16 T2DM patients revealed a 10.4-times increase on average in MBD2 mRNA levels in patients compared to controls (Figure 1a). The separate analysis in each patient group showed the highest increase in the newly-diagnosed (treatment-naïve) T2DM patients; 12.9-times average increase, followed by 10.4-times average increase in patients with T2DM duration of less than 5 years and 6.1-times average increase in T2DM patients with duration of the disease of more than 5 years (Figure $1 b$ to $1 d$ ).

Methylation Analysis of Genes Connected to Stress and Toxicity in Patients with T2DM. Using EpiTect Methyl II Signature PCR Array (Qiagen Sciences Inc.), the methylated and non methylated fraction of 11 genes, connected to cellular response to stress and toxicity, were successfully analyzed in all DNA pools. The methylation fraction of these genes is represented in Table 3.

In the healthy controls, the methylated fraction was $0 \%$ in six of the analyzed genes, ranged from

Table 3. Methylated (M) fraction of the analyzed genes in four DNA pools.

\begin{tabular}{|l|c|c|c|c|}
\hline Genes & $\begin{array}{c}\text { Controls } \\
\text { M Fraction (\%) }\end{array}$ & $\begin{array}{c}\text { Newly-Diagnosed T2DM } \\
\text { M Fraction (\%) }\end{array}$ & $\begin{array}{c}\text { T2DM Duration } \leq \mathbf{5} \text { Years } \\
\text { M Fraction (\%) }\end{array}$ & $\begin{array}{c}\text { T2DM Duration >5 Years } \\
\text { M Fraction (\%) }\end{array}$ \\
\hline BRCA1 & 0.0 & 5.9 & 0.5 & 47.8 \\
\hline CCND1 & 0.0 & 13.6 & 14.7 & 34.1 \\
\hline Gadd45A & 0.0 & 0.0 & 0.7 & 0.0 \\
\hline Gadd45G & 0.0 & 4.9 & 4.8 & 0.0 \\
\hline GDF15 & 98.5 & 98.4 & 97.7 & 95.9 \\
\hline Gpx3 & 1.4 & 23.6 & 13.1 & 15.7 \\
\hline Insig1 & 2.4 & 10.4 & 4.9 & 32.0 \\
\hline Prdx2 & 7.3 & 22.3 & 22.4 & 7.6 \\
\hline Rara & 0.0 & 13.2 & 6.6 & 23.3 \\
\hline SCARA3 & 3.5 & 8.1 & 20.2 & 10.2 \\
\hline Tp53 & 0.0 & 5.9 & 6.4 & \\
\hline
\end{tabular}



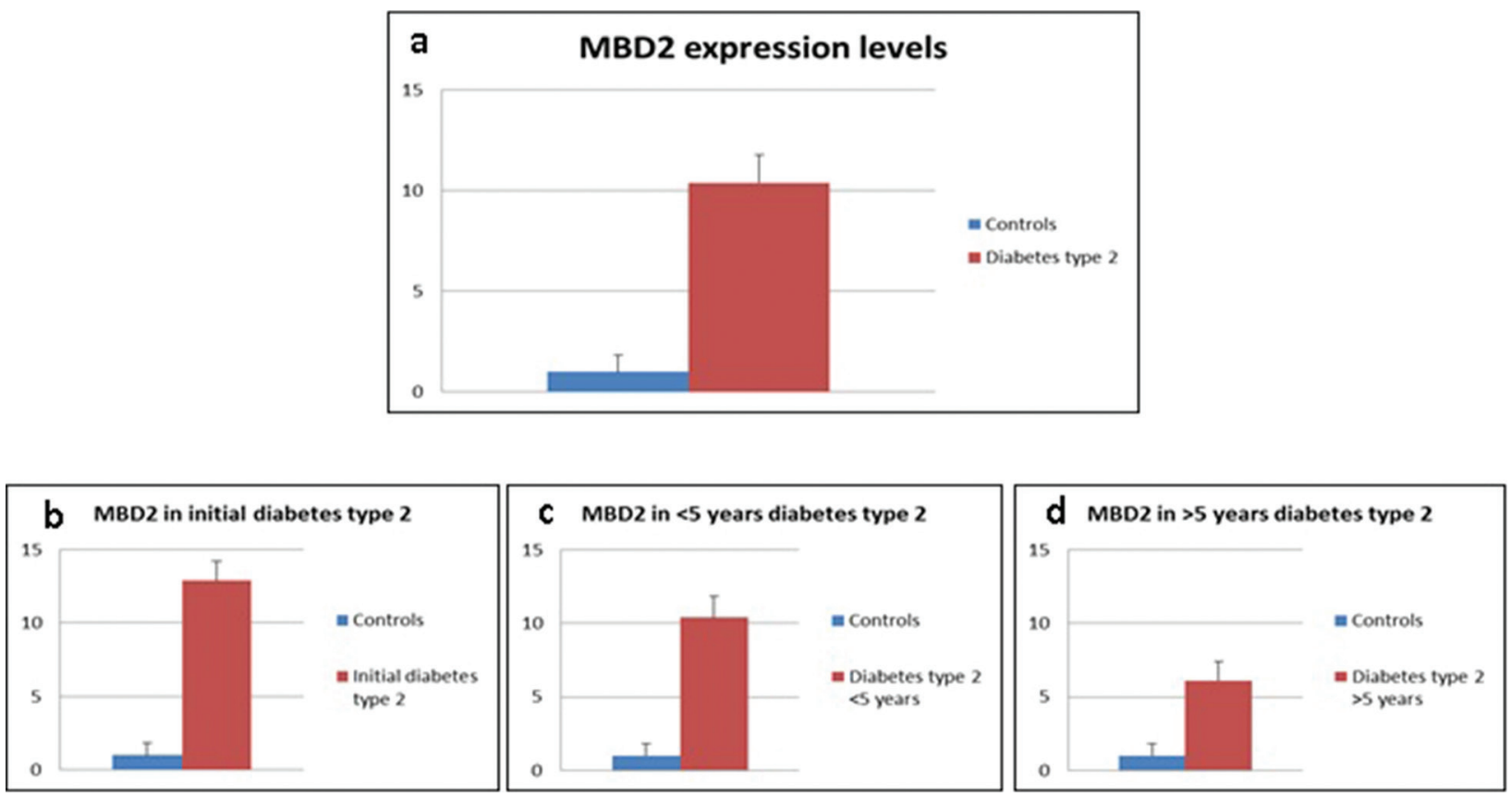

Figure 1. $M B D 2$ expression levels in patients with T2DM compared to control subjects: $a$ ) in all patients; $\mathrm{b}$ ) in patients with newly-diagnosed T2DM; c) in patients with T2DM duration of less than 5 years; d) in patients with T2DM duration of more than 5 years.

1.4 to $7.3 \%$ in four genes and was $98.5 \%$ for the GDF15 gene. In newly-diagnosed T2DM patients, the methylated fraction was $0 \%$ only in one gene, $98.4 \%$ in GDF 15 and increased to values between 4.9 and $23.6 \%$ for the remainder of the genes. In patients with T2DM duration of less than 5 years, the methylated fraction was $97.7 \%$ for $G D F 15$ and varied between 0.5 and $22.4 \%$ for all other genes. Among T2DM patients with duration of more than 5 years, the methylated fraction was $0 \%$ in two of the analyzed genes, $95.9 \%$ for GDF 15 and ranged from 7.6 to up to $47.8 \%$ for the rest of the genes.

The genes Gadd45G, Gpx3 and RARA showed the highest methylated fraction in newly-diagnosed T2DM patients, probably due to the poor glycemic control. Five genes were with consistently increased methylated fraction during the course of the disease: BRCA1, CCND1, Prdx2, SCARA3 and Tp53 (Figure $2)$. There was a slight decrease in the methylated fraction of GDF15 with increase in the duration of T2DM.

\section{DISCUSSION}

The epigenetic status of certain genes in the human genome is affected by external environmental factors, pathological conditions, as well as during the normal processes of aging. Type 2 diabetes mellitus is a common disease, the pathogenesis of which involves factors such as genetic susceptibility, obesity, decreased physical activity, imbalanced nutrition and age. Age is an important factor that increases the risk of T2DM and furthermore, increasing age and T2DM both lead to decreased oxidation capacity and mitochondrial dysfunction. The mechanisms of these processes can be influenced by both genetic factors and by epigenetic processes. Literature data suggest that aging of the individual changes the epigenetic status of the respiratory chain genes $[1,5,6,13]$.

Methylation of $\mathrm{CpG}$ dinucleotides is an important epigenetic mechanism used by vertebrate cells to repress transcription of many tissue-specific genes [14]. DNA methylation is the major modification of eukaryotic genomes and plays an essential function in mammalian progression. Methyl-CpG binding domain proteins are capable of binding specifically to methylated DNA and MBD1 and MBD2 can in addition repress transcription from methylated gene promoters [15]. In light of the functional significance of MBD proteins in the epigenomic landscape, we aimed to provide knowledge about the expression of the $M B D 2$ gene in blood samples of patients with T2DM and hence to test it as a distinct epigenetic biomarker for disease development. 

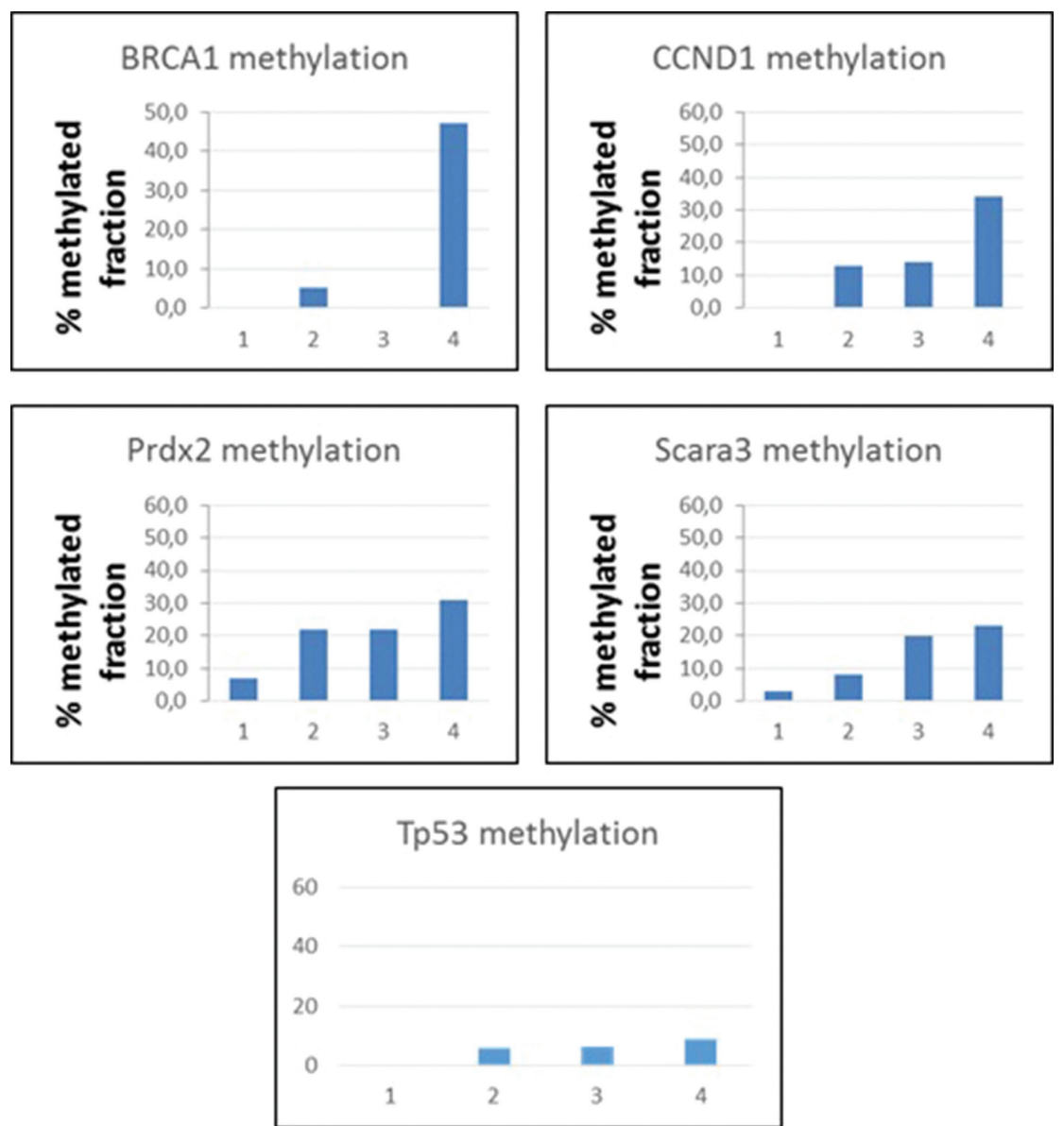

Figure 2. Increase in the methylated fraction of BRCA1, CCND1, Prdx2, SCARA3 and Tp53 during the course of T2DM.

In the present study, we detected a 10.4-times average increase in mRNA expression levels of $M B D 2$ in patients with T2DM compared to controls. When patients were stratified according to the duration of the disease, this increase was highest in patients with newly-diagnosed treatment naïve diabetes and it decreased with the increase in the duration of the disease still keeping the overexpressed levels. These findings are in accordance with previous data pointing out that high glucose levels induce DNA methylation by up-regulating DNMT3a and MBD2 [16]. A probable explanation for the decrease in MBD2 expression in T2DM with a duration of more than 5 years was the improved glycemic control of the treated patients. Nevertheless, the expression was still high when compared to the controls, indicating continuing dysregulation of methylation processes as a result of the disease, despite treatment.

The present study also involved analysis of the methyl-ation status of 22 genes, connected to cellular stress and toxicity, in four DNA pools of patients with newly-diagnosed T2DM, patients with T2DM duration of less or more than 5 years and in healthy controls. Eleven of these genes were successfully analyzed in all DNA pools. We were able to evaluate the average methylated fraction for every gene in each DNA pool. Notably, most of the analyzed genes lacked methylated fractions in healthy individuals, thus indicating an active transcriptional state. The only exception was GDF15, which was almost totally methylated in healthy controls. It is an extracellular secretory protein, which is expressed at high levels in placenta during development. Its role in the early stages of endochondrial bone formation, hematopoietic develop-ment, embryonic implantation and placental function has been reported. Obviously, the gene expression is silenced during adult life by DNA methylation. In our patients, however, this methylation was slightly decreased, indicating some transcriptional activation. Recently, GDF15 
was identified as one of the important plasma markers that correlates with the cardiometabolic syndrome [17]. Higher levels of GDF15 are associated with increased cardiovascular and non cardiovascular mortality as it plays a pivotal role in the development and progression of cardiovascular diseases such as heart failure, coronary artery disease, atrial fibrillation, diabetes, cancer and cognitive impairment $[18,19]$. The decreasing methylation of GDF15 in the course of T2DM is in line with the cardiovascular complications of the disease.

Five genes: BRCA1, CCND1, Prdx2, SCARA3 and $T p 53$, showed consistent increase in DNA methylated fraction in the course of T2DM. The methylated fraction of the $B R C A 1$ gene is increased over 40-times in T2DM. BRCA1 is a tumor suppressor gene and its protein product is part of a complex involved in the repair of DNA double-strand breaks. This DNA reparation is performed by homologous recombination in which the homologous intact sequence from the sister chromatid is used to recover the broken segment. It is considered that there is a strong link between aberrant methylation of the BRCA1 in white blood cells and breast cancer-related molecular changes, which indicate the potential predisposition of BRCA1 dysmethylation carriers for developing breast cancer [20].

In the course of T2DM, the methylated fraction of the CCND1 gene increases over 30-times. This gene is a regulator of the cell cycle (cyclin-dependent kinase). Together with CDK4 and CDK6, its protein product is involved in a complex in the G1/S transition. It has been reported that the methylation status of CCND1 is not associated with its expression [21].

The methylated fraction of $\operatorname{Prdx} 2$ increases by more than 30-times in the course of T2DM. This gene encodes a member of the peroxiredoxin family of antioxidant enzymes, which reduces hydrogen peroxide and alkyl hydro-peroxides. The encoded protein plays an antioxidant protective role in cells. Previous studies have shown that the deletion of Prdx2 leads to increased expression of vascular cell adhesion molecule-1, intracellular adhesion molecule-1 and monocyte chemo-attractant protein-1, which are markers of endothelial dysfunction and also inducers of atherosclerotic plaques $[22,23]$. This shows that the increased methylation of $P r d x 2$ in T2DM leads to loss of its antioxidant protective and antiatherosclerotic role.
The methylated fraction of SCARA3 shows a more than 20-fold increase in the course of T2DM. The SCARA3 gene encodes a macrophage scavenger receptor-like protein. Its protein discharges reactive oxygen radicals and plays an important role in the protection against oxidative stress. It has been shown that oxidative stress induces the expression of SCARA3 [24]. The increased methylation of SCARA3 in T2DM patients is another epigenetic hint for the loss of oxidative protection in the pathogenesis and course of the disorder.

The methylated fraction of the universal tumor suppressor gene Tp53 increases 10-times in the course of T2DM. The p53 protein regulates key cellular processes, including cell-cycle arrest, DNA repair, apoptosis, and senescence in response to stress signals. It becomes stabilized and activated in short time in response to DNA damage, hypoxia, hyperproliferation, and other types of cellular stress [25]. It is the most commonly inactivated gene in human cancers. Taking into account that increased methylation is one of the mechanisms for gene silencing, the observed epigenetic pattern of $T p 53$ in our study points to a possible molecular pathway in the eventual cancer development in T2DM.

The increasing methylated fraction of $B R C A 1$ and $T p 53$ observed in the present study was in line with several meta-analyses, which show that T2DM patients are at increased risk from cancer, as follows: liver cancer 2.5-times higher [26]; endometrial 2.1 [27]; pancreatic 1.82 [28]; urinary bladder 1.43 [29]; kidney 1.42 [30]; colorectal 1.3 [31] and breast cancer 1.2-times higher risk [32].

In conclusion, the detected higher expression of $M B D 2$ in patients at different stage of T2DM indicated general dysregulation of the DNA methylation processes as a result of the disease. In line with this result, of the analyzed stress and cell cycle regulation genes, five showed consistenly increasing methylated fraction with the increase in T2DM duration: BRCA1, CCND1, Prdx2, SCARA3 and Tp53. The elevated methylation of genes $\operatorname{Prdx} 2$ and SCARA3 showed that their role in oxidative stress protection decreases due to elevated methylation and may cause T2DM compli-cations. Genes BRCA1, CCND1 and $T p 53$ are related to tumorigenesis. We refrain from premature conclusion for $C C N D 1$ as its methylation does not reflect its expression. On the other hand, the increased methylation of $B R C A 1$ and $T p 53$ was 
associated with cancer development, which was really more common in T2DM patients [26-32]. This finding unravels a possible epigenetic link between T2DM and cancer development.

The results from the present study require broadening of the set of genes analyzed for epigenetic changes in T2DM. Furthermore, the results for the genes with consistently increasing methylation in T2DM should be further validated via expression analysis. In case these results are confirmed, the implementation of antioxidant protection in the therapeutic approach for T2DM seems completely justified from an epigenetic point of view.

\section{ACKNOWLEDGMENTS}

We would like to thank all the subjects who provided blood samples. Sample collection and experimental analyses were supported by Grant 40/2014, Medical University, Sofia, Bulgaria.

Declaration of Interest. The authors report no conflicts of interest. The authors alone are responsible for the content and writing of this article.

\section{REFERENCES}

1. Robertson RP. Chronic oxidative stress as a central mechanism for glucose toxicity in pancreatic islet $\beta$ cells in diabetes. J Biol Chem. 2004; 279(41): 42351-42354.

2. Hari Kumar KVS, Modi KD. Twins and endocrinology. Indian J Endocrinol Metab. 2014; 18(Suppl 1): S48-S52.

3. Bramswig NC, Kaestner KH. Epigenetics and diabetes treatment: An unrealized promise? Trends Endocrinol Met. 2012; 23(6): 286-291.

4. Kommoju U, Reddy BM. Genetic etiology of type 2 diabetes mellitus: A review. Int J Diab Dev Ctries. 2011; 31(2): 51-64.

5. Lyssenko V, Laakso M. Genetic screening for the risk of type 2 diabetes: Worthless or valuable? [Research Support, Non-U.S. Gov't Review]. Diabetes Care. 2013; 36(Suppl 2): S120-S126.

6. Zimmet P, Alberti KGMM, Shaw J. Global and societal implications of the diabetes epidemic. [10.1038/414782a]. Nature. 2001; 414(6865): $782-787$.
7. Ling C, Groop L. Epigenetics: A molecular link between environmental factors and type 2 diabetes. Diabetes. 2009; 58(12): 2718-2725.

8. Berger SL, Kouzarides T, Shiekhattar R, Shilatifard A. An operational definition of epigenetics. Gene Dev. 2009; 23(7): 781-783.

9. Bernstein BE, Meissner A, Lander ES. The mammalian epigenome. Cell. 2007; 128(4): 669-681.

10. Tsai H-C, Baylin SB. Cancer epigenetics: Linking basic biology to clinical medicine. Cell Res. 2011; 21(3): 502-517.

11. Patra SK, Deb M, Patra A. Molecular marks for epigenetic identification of developmental and cancer stem cells. Clin Epigenetics. 2011; 2(1): 27-53.

12. Klose RJ, Bird AP. Genomic DNA methylation: the mark and its mediators. [Research Support, Non-U.S. Gov’t Review]. Trends Biochem Sci. 2006; 31(2): 89-97. doi: 10.1016/j. tibs.2005.12.008.

13. Keating ST, El-Osta A. Epigenetic changes in diabetes. [Research Support, Non-U.S. Gov't Review]. Clin Genet. 2013; 84(1): 1-10. doi: 10.1111/cge. 12121 .

14. Bird A. DNA methylation patterns and epigenetic memory. [Research Support, Non-U.S. Gov't Review]. Genes Dev. 2002; 16(1): 6-21.

15. Clouaire T, Stancheva I. Methyl-CpG binding proteins: Specialized transcriptional repressors or structural components of chromatin? Cell Mol Life Sci. 2008; 65(10): 1509-1522.

16. Chavali V, Tyagi N, Tyagi SC, Mishra PK. MiR-133 as an epigenetic regulator of diabetic heart failure. FASEB J. 2012; 26(1_MeetingAbstracts): 1057.1022.

17. Adela R, Banerjee SK. GDF-15 as a target and biomarker for diabetes and cardiovascular diseases: A translational prospective. J Diabetes Res. 2015; 2015: 4090842. doi: 101155/2015/490842.

18. Lindahl B. The story of growth differentiation factor 15: another piece of the puzzle. Clin Chem. 2013; 59(11): 1550-1552.

19. Wallentin L, Hijazi Z, Andersson U, Alexander JH, De Caterina R, Hanna M, et al. Growth differentiation factor 15 , a marker of oxidative stress and inflammation, for risk assessment in patients with atrial fibrillation: Insights from the 
Apixaban for Reduction in Stroke and Other Thromboembolic Events in Atrial Fribrilation (ARISTOTLE) trial. Circulation; 2014; 130(21): $1847-1858$.

20. Al-Moghrabi N, Nofel A, Al-Yousef N, Madkhali $\mathrm{S}$, Bin Amer SM, Alaiya A, et al. The molecular significance of methylated BRCA1 promoter in white blood cells of cancer-free females. [Research Support, Non-U.S. Gov't]. BMC Cancer. 2014; 14: 830. doi: 10.1186/1471-2407-14-830.

21. Walker BA, Wardell CP, Chiecchio L, Smith EM, Boyd KD, Neri A, et al. Aberrant global methylation patterns affect the molecular pathogenesis and prognosis of multiple myeloma. [Randomized Controlled Trial Research Support, NonU.S. Gov't]. Blood. 2011; 117(2): 553-562.

22. Brevetti G, Schiano V, Chiariello M. Cellular adhesion molecules and peripheral arterial disease. (Review). Vasc Med. 2006; 11(1); 39-47.

23. Park JG, Yoo JY, Jeong SJ, Choi JH, Lee MR, Lee MN, et al. Peroxiredoxin 2 deficiency exacerbates atherosclerosis in apolipoprotein Edeficient mice. [Research Support, Non-U.S. Gov't]. Circ Res. 2011; 109(7): 739-749.

24. Brown CO, Schibler J, Fitzgerald MP, Singh N, Salem K, Zhan F, et al. Scavenger receptor class A member 3 (SCARA3) in disease progression and therapy resistance in multiple myeloma. Leukemia Res. 2013; 37(8): 963-969.

25. Scoumanne A, Chen X. Protein methylation: A new regulator of the p53 tumor suppressor. Histol Histopathol. 2008; 23(9): 1143-1149.
26. El-Serag HB, Hampel H, Javadi F. The association between diabetes and hepatocellular carcinoma: A systematic review of epidemiologic evidence. Clin Gastroenterol Hepatol. 2006; 4(3): 369-380.

27. Friberg E, Orsini N, Mantzoros C, Wolk A. Diabetes mellitus and risk of endometrial cancer: $\mathrm{A}$ meta-analysis. Diabetologia. 2007; 50(7): 13651374.

28. Huxley R, Ansary-Moghaddam A, Berrington de Gonzalez A, Barzi F, Woodward M. Type-II diabetes and pancreatic cancer: A meta-analysis of 36 studies. (Meta-Analysis). Br J Cancer. 2005; 92(11): 2076-2083.

29. Larsson S, Orsini N, Brismar K, Wolk A. Diabetes mellitus and risk of bladder cancer: A metaanalysis. Diabetologia. 2006; 49(12): 2819-2823.

30. Larsson S, Wolk A. Diabetes mellitus and incidence of kidney cancer: A meta-analysis of cohort studies. Diabetologia. 2011; 54(5): 10131018 .

31. Larsson SC, Orsini N, Wolk A. Diabetes mellitus and risk of colorectal cancer: A meta-analysis. J Natl Cancer I. 2005; 97(22): 1679-1687.

32. Larsson SC, Mantzoros CS, Wolk A. Diabetes mellitus and risk of breast cancer: A meta analysis. Int J Cancer. 2007; 121(4): 856-862. 
